Fieberanfall inducirt, wie es beobachtet wurde, wenn epileptische Anfälle einen Zustand der Erregung mit Temperatursteigerung herbeiführen, wenn die epileptiformen Anfülle, die im Verlaufe der allgemeinen Paralyse auftreten, mit einer bedeutenden Temperatursteigerung einhergehen (Clouston), wenn bei Geisteskranken periodisch Agitationszustände sich einstellen, welche regelmässig auch Fiebertemperaturen veraulassen (Westphal), so müssen wir anerkennen, dass die Fieberquelle ihren Sitz auch im centralen Nervensystem haben kann - ganz in Uebereinstimmung damit, dass wir den Nerven einen Einfluss auf den Stoffwechsel der Gewebe nicht nur zur Zeit der evidenten Functionirung, sondern auch während der Ruhe zuerkennen."

S. 507. „Sollen wir nun nach dem heutigen Stande unserer Erkenntniss das Fieber definiren, so können wir dasselbe als eine Störung bezeichnen, in welcher die Umsetzung der lebenden Materie des Körpers, in hervorragender Weise diejenige der eiweissreichen Substanzen der Gewebe, des sog. lebendigen Eiweiss (Pflüger), gesteigert ist, ohne dass die Art dieses chemischen Stoffwandels qualitativ anders geworden wäre wie normal. Diese Steigerung kann vom Nervensystem, aber wahrscheinlich auch vom Blut aus hervorgerufen werden. Unter den mannichfaltigen Apparaten des Körpers, welche fieberhaft erregt werden, steht der motorische Apparat des Gefässsystems, das Herz und die Gefässmusculatur, obenan, beherrscht von dem vasomotorischen Nervensystem, welchem daher in der Fieberbewegung eine Hauptrolle zufällt."

\title{
IX.
}

\section{Ueber Actinomyces.}

Berichtigung zu einem Referate des Herrn Prof. Johne in Dresden.

Von Dr. Oscar Israel, Assistenten am pathologischen Institute zu Berlin.

In No. 4 der "Fortsehritte der Medicin" vom 15. Februar d. J. referirt Herr Johne über meine Arbeit "Ueber die Cultivirbarkeit der Actinomyces“ (dies. Archiv Bd. 95. S. 140).

Nachdem der Redacteur der "Fortschritte", Herr Friedländer, einer Erwiderung meinerseits wegen Platzmangels die A ufnahmeversagt 
hat, mag es hier genügen, dieses Verfabren mitzutheilen und zugleich eine von Herrn Johne bezweifelte, nicht unwichtige Thatsache richtig zu stellen.

Ich hatte (1. c. S. 1.4) ausgesprochen, dass die grosse Vulnerabilität des Strahlenpilzes eine Erklärung abgebe für das Feblschlagen früherer Culturversuche und Impfungen, und dass auch $\mathrm{P}$ onfick die Erfahrung gemacht habe, dass nur Geschwulststäcke mit Pilzkörnern zur Uebertragung der Krankheit tauglich wären, werde durch die erwähnten Eigenschaften des Actinomyces, wie sie in den Culturen hervortraten, erklärt.

Herr Johne bestreitet nun ganz entschieden, dass Ponfick eine derartige Erfahrung gemacht habe, und zwar thut er dies in einer Form, welche auf den weniger mit den Einzelheiten vertrauten Leser leicht den Eindruck machen könnte, als häite ich mir ein falsches Citat aus Ponfick's Publicationen construirt.

Ich gestehe zu, dass der Ausdruck „Erfahrung“ unzweckmässig gewählt sein mag, für eine Thatsache, die ihrem Entdecker nicht zum vollen Bewusstsein gekommen zu sein scheint, denn Ponfick spricht diese Beobachtung nicht direct aus, wahrscheinlich weil zu jener Zeit die Aufmerksamkeit nicht auf diesen Punkt gelenkt war; aber eine sorgfältige Durchsicht seiner Mittheilungen über seine Impfungen ergiebt, dass seine Uebertragungsversuche negativ ausfielen, sobald er in Kochsalzlösung fein vertheilte Pilzkörner, ohne anhaftendes Gewebe benutzte. Ich habe mich durch eine erneute Durchsicht überzeugt, dass mir kein Irrthum dabei begegnet ist und darf mich daher wohl berechtigt halten, diese Wahrnehmung auch Herrn Jobne gegenüber aufrecht zu erhalten.

Wenn Herr Johne aber verlangt, dass man seine 3 Versuche ernst nehme, deren Gelingen, wie er selbst sagt (Zeitschr. für Thiermedicin Bd. VII. S. 181), "vor dem Richterstuhle strengster Kritik" nicht stricte bewiesen ist, so stellt er damit ein Verlangen, welchem ich von meinem wissenschaftlichen Standpunkte aus nicht entsprechen kann. Es erscheint mir hierbei ganz gleichgültig, ob ihm sein vermeintlicher Nachweis bereits geglückt war "zu einer Zeit, wo Ponfick nach dessen eigener mündlichen Mittheilung noch kein einziger Impfversuch gelungen war", oder erst nach Ponfick's verdienstroller Untersuchung.

Wenn Herr $J_{0}$ hne mir ausserdem die Unvollständigkeit meiner botanischen Angaben vorwirft, so ist dort wohl zu erwähnen, dass ich mein Urtheil über die botanischen Verbältnisse des Pilzes ausdrücklich reservirt habe, was bei der Schwierigkeit der Aufgabe gewiss gerechtfertigt erscheint. Vielleicht wäre die Bescheidenheit des Referenten mehr hervorgetreten, wenn er, der nicht umhin kann, in demselben Referat die Mangelhaftigkeit seiner eigenen Culturversuche zuzugestehen, mit seinem Urtheil so lange gewartet hätte, bis er selber weiter gekommen wäre. -

Bd. XCV. Hft. 3 S. 484 lies: Virus statt Urins 